\title{
Urological injuries during obstetric and gynaecological procedures: a retrospective analysis over a period of eleven years
}

\author{
Rashmi S. Desai*, Sunil Kumar K.
}

Department of Obstetrics and Gynecology, SDM College of Medical Sciences, Dharwad, Karnataka, India

Received: 06 April 2016

Accepted: 07 May 2016

\section{*Correspondence:}

Dr. Rashmi S. Desai,

E-mail: drrashmi.mankani@gmail.com

Copyright: ( $)$ the author(s), publisher and licensee Medip Academy. This is an open-access article distributed under the terms of the Creative Commons Attribution Non-Commercial License, which permits unrestricted non-commercial use, distribution, and reproduction in any medium, provided the original work is properly cited.

\begin{abstract}
Background: To determine frequency and nature of urological injuries in obstetric and gynaecological procedures and their consequences and mode of management in a tertiary care hospital SDM Medical college and hospital, Dharwad, India. Methods: A retrospective study of all obstetric and gynaecological surgeries over a period of 11 years from January 2004 to December 2014 was carried out at Department of Obstetrics and Gynaecology, SDM Medical College and Hospital, Dharwad, India. Cases with the documented urological injuries were analyzed further. A total of 18,250 patients underwent obstetric and gynaecological procedures like lower segment caesarean section, various types of hysterectomies were analyzed. Cases with urologic injuries were identified and analyzed for risk factor, timing of diagnosis, their management and consequences.

Results: Out of 18,250 patients undergoing various surgeries, $37(0.2 \%)$ patients had bladder injury and $4(0.02 \%)$ patients had ureteric injury. In gynecologic procedures, the incidence of bladder injury was highest in radical hysterectomy ( 2 out of 79, 2.5\%) followed by TLH/LAVH (4 out of 299, 1.3\%), NDVH (7 out of 490, 1.4\%) TAH (5 out of $1360,0.37 \%$ ), laparotomy (1 out of 347, 0.29\%) and vaginal hysterectomy (3 out of 1529, 0.2\%). Three ureteric injuries were noted in cases of TLH/LAVH (3 out of 299) and one in case of TAH (1 out of 1360, 0.07\%).

Conclusions: Even though urological injuries are statistically rare, they are responsible for significant morbidity. Bladder injuries are more common, but are easy to manage with earlier diagnosis. Ureteric injuries which are usually diagnosed late and hence cause more morbidity than bladder injuries.
\end{abstract}

Keywords: Obstetric and Gynaecologic surgery, Urologic injury, Complications

\section{INTRODUCTION}

Urological injuries which involve damage to the urinary bladder and ureter are not uncommon in obstetric and gynaecological surgeries. This is due to close anatomical proximity of urogenital systems. In fact $75 \%$ of iatrogenic urinary tract injuries are due to gynaecologic surgeries. ${ }^{1}$ Urinary tract injury complicates an estimated 0.2 to $1 \%$ of all gynaecologic procedures and pelvic operations. $^{2}$ Even though the incidence of urologic injuries appears small, but due to very high number of gynaecologic surgeries performed, there are quite a few urologic injuries and these urological complications carry a significant amount of morbidity in the form of greater blood loss, longer operative time, more febrile morbidity, longer hospital stay and sometimes may need second surgery.

The incidence of these injuries varies depending on the type of gynaecologic surgery performed, complexity of surgery, altered pelvic anatomy due to infections, previous surgeries, adhesions, previous radiation therapy, location of cervical or broad ligament fibroids and intraoperative complication like severe bleeding. ${ }^{3}$ Introduction of laparoscopic surgeries have increased the incidence to some extent, although with achievement of the learning curve the frequency of bladder injury has declined but that of ureteric injury is still high. ${ }^{4}$ With the 
increased knowledge of these injuries and improvements in surgical techniques, the incidences of these injuries have reduced and they are diagnosed earlier and better managed in present day practice. Hence periodic analysis of these iatrogenic injuries will give information about their changing trends, incidence in various surgeries, the time of diagnosis, their management and overall morbidity caused them. Therefore this retrospective analysis of all the urologic injuries caused during various obstetric and gynaecological surgeries was carried out.

\section{METHODS}

A retrospective analysis of case records of patients who underwent various obstetric and gynaecologic surgeries in SDM Medical College and hospital over a period of 11 years from January 2004 to December 2014 was carried out. Gynaecological procedures were classified as Total abdominal hysterectomy (TAH), Non-descent Vaginal Hysterectomy (NDVH), Vaginal Hysterectomy with or without pelvic floor repair (VH), Radical Hysterectomy (RH), laparotomy (for ovarian cystectomy, salphingectomy, staging laparotomy), Total laparoscopic Hysterectomy (TLH) or Laparoscopic Assisted Vaginal Hysterectomy (LAVH), diagnostic hysterolaproscopy (DHL), Myomectomy, Fothergill's surgery and surgery for the Vault Prolapse. Lower segment Caesarean Section (LSCS), Caesarean hysterectomy, hysterotomy and puerperal Bilateral Abdominal Tubectomy (BAT) were classified as obstetric procedures. Total numbers of surgeries performed in these various subcategories were noted. Minor obstetric and gynaecological procedures, where the possibility of urologic injury is almost negligible, were not included in this analysis. The procedures excluded for this reason were: medical termination of pregnancy, cervical encircalage and gynaecological procedures like dilatation and curettage, conisation, laparoscopic tubal ligation and thermal balloon ablation.

Any accidental urological injuries that happened during the operative procedures were marked in the record book and incident report forms were filled for the same. We noted that 41 patients had urological injuries during various obstetric and gynaecologic surgeries, as marked in the record book. This was confirmed by cross matching with the incident report forms. The case records of these patients were retrieved and were analysed for surgical procedure during which the urologic injury occurred, underlying condition for which surgery was being carried out, the site of injury (bladder or ureter), time of identification (whether intraoperative or postoperative), treatment modality, complications and consequences.

\section{RESULTS}

Total of 18,250 patients had undergone various surgeries during the eleven years, of which 4762 were gynaecologic surgeries and 13488 obstetric surgeries. Out of 18,250 patients undergoing various surgeries, $37(0.2 \%)$ patients had bladder injury and 4(0.02\%) patients had ureteric injury (Table 1). Of 10843 LSCS and 2612 cases of bilateral abdominal tubectomies, there was 12 and 1 case of bladder injury respectively. There was one bladder injury in 8 cases of caesarean hysterectomies performed and no injuries in any of the hysterotomies. There was no ureteric injury in any of the obstetric surgeries. All but one bladder injury in obstetric surgeries were identified intraoperatively and primary repair was done by closing urinary bladder in two layers using vicryl 2-0 suture (Table 2). Every patient received a urethral catheter, which was left indwelling for at least 10 to 14 days. In one case where LSCS was carried out following the failure of progression in second stage of labour, the patient developed vesico-vaginal fistula (VVF) postoperatively. Entrapment of bladder in lower segment sutures was suspected confirmed with cystography; secondary repair was done after three months.

Table 1: Incidence of urologic injuries in various types of surgeries.

\begin{tabular}{|c|c|c|c|}
\hline Operation & $\begin{array}{l}\text { Total } \\
\text { number of } \\
\text { cases }\end{array}$ & $\begin{array}{l}\text { Bladder } \\
\text { injury } \\
\mathbf{n}(\%)\end{array}$ & $\begin{array}{l}\text { Ureteric } \\
\text { Injury } \\
\text { n (\%) }\end{array}$ \\
\hline $\begin{array}{l}\text { Total abdominal } \\
\text { hysterectomy }\end{array}$ & 1360 & $\begin{array}{l}5 \\
(0.37 \%)\end{array}$ & $1(0.074 \%)$ \\
\hline $\begin{array}{l}\text { Non-decent vaginal } \\
\text { hysterectomy }\end{array}$ & 490 & $\begin{array}{l}7 \\
(1.43 \%)\end{array}$ & 0 \\
\hline $\begin{array}{l}\text { Vaginal } \\
\text { hysterectomy }\end{array}$ & 1529 & $3(0.2 \%)$ & 0 \\
\hline TLH/LAVH & 299 & $4(1.3 \%)$ & $3(1 \%)$ \\
\hline $\begin{array}{l}\text { Diagnostic } \\
\text { hysteron- } \\
\text { laparoscopy }\end{array}$ & 530 & $1(0.18 \%)$ & 0 \\
\hline $\begin{array}{l}\text { Radical } \\
\text { hysterectomy }\end{array}$ & 79 & $2(2.5 \%)$ & 0 \\
\hline Laparotomy & 347 & $\begin{array}{l}1 \\
(0.29 \%)\end{array}$ & 0 \\
\hline Myomectomy & 76 & 0 & 0 \\
\hline Fothergill operation & 47 & 0 & 0 \\
\hline Vault prolapse & 5 & 0 & 0 \\
\hline $\begin{array}{l}\text { Total } \\
\text { gynaecological } \\
\text { procedures }\end{array}$ & 4762 & $\begin{array}{l}23 \\
(0.48 \%)\end{array}$ & $4(0.08 \%)$ \\
\hline LSCS & 10843 & $\begin{array}{l}12 \\
(0.11 \%)\end{array}$ & 0 \\
\hline $\begin{array}{l}\text { Bilateral abdominal } \\
\text { tubectomy }\end{array}$ & 2612 & $\begin{array}{l}1 \\
(0.04 \%)\end{array}$ & 0 \\
\hline $\begin{array}{l}\text { Obstetric } \\
\text { hysterectomy }\end{array}$ & 8 & $\begin{array}{l}1 \\
(12.5 \%)\end{array}$ & 0 \\
\hline Hysterotomy & 25 & 0 & 0 \\
\hline $\begin{array}{l}\text { Total obstetric } \\
\text { procedures }\end{array}$ & 13488 & $\begin{array}{l}14 \\
(0.103 \%)\end{array}$ & 0 \\
\hline
\end{tabular}

TLH: Total Laparoscopic Hysterectomy; LAVH: Laparoscopic assisted Vaginal Hysterectomy; LSCS: Lower Segment Caesarean Section. 
Table 2: Analysis of cases involving urologic injuries.

\begin{tabular}{|c|c|c|c|c|}
\hline $\begin{array}{l}\text { Surgery during which } \\
\text { injury occurred (N) }\end{array}$ & Time of identification & Treatment modality & $\begin{array}{l}\text { Duration of } \\
\text { hospital stay }\end{array}$ & Blood transfusion \\
\hline \multicolumn{5}{|l|}{ Bladder injuries } \\
\hline $\begin{array}{l}\text { TAH } \\
(5)\end{array}$ & 5:Intra op & All primary repair & 14- 21 days & 1 patient \\
\hline $\begin{array}{l}\text { NDVH } \\
\text { (7) }\end{array}$ & $\begin{array}{l}\text { 6:Intra op } \\
\text { 1:Post op }\end{array}$ & $\begin{array}{l}\text { 6: primary repair } \\
\text { 1: VVF repair }\end{array}$ & 10-21 days & 2 cases \\
\hline VH (3) & 3:Intra op & 3: primary repair & 5- 10 days & Nil \\
\hline Laparotomy (1) & 1:Intra op & 1:Primary repair & 14 days & yes \\
\hline TLH: bladder injury (4) & 4:Intra op & $\begin{array}{l}\text { 4: laparotomy and } \\
\text { primary repair }\end{array}$ & 10-14 days & No \\
\hline $\begin{array}{l}\text { Radical Hysterectomy } \\
\text { (2) }\end{array}$ & $\begin{array}{l}\text { 1: Intra op } \\
1 \text { : Postop }\end{array}$ & $\begin{array}{l}\text { 1: primary repair } \\
\text { 1: VVF repair }\end{array}$ & 14- 21 days & 2 cases \\
\hline $\begin{array}{l}\text { LSCS } \\
(12)\end{array}$ & $\begin{array}{l}\text { 11:Intra op } \\
\text { 1:Post op }\end{array}$ & $\begin{array}{l}\text { 11: primary repair } \\
\text { 1: VVF repair after } 3 \\
\text { months }\end{array}$ & 10-12 days & Nil \\
\hline BAT (1) & 1:Intra op & 1: primary repair & 6 days & Nil \\
\hline $\begin{array}{l}\text { Obstetric hysterectomy } \\
\text { (1) }\end{array}$ & 1:Intra op & 1: primary repair & 24 days & 1 case \\
\hline DHL (1) & 1: Intra op & 1: Primary repair & 14 days & Nil \\
\hline \multicolumn{5}{|l|}{ Ureteric injury } \\
\hline TLH Ureteric injury (3) & $\begin{array}{l}\text { 1:Intra op } \\
2: \text { Post op }\end{array}$ & $\begin{array}{l}\text { 1: laparotomy, end to } \\
\text { end anastomosis } \\
\text { 1: ureteric stenting } \\
\text { 1: ureteric } \\
\text { reimplantation }\end{array}$ & 14-21 days & 1 case \\
\hline $\begin{array}{l}\text { TAH } \\
\text { (1) }\end{array}$ & 1: Intra op & $\begin{array}{l}\text { 1:Ureteric re- } \\
\text { implantation with neo- } \\
\text { bladder creation }\end{array}$ & 22 days & 1 case \\
\hline
\end{tabular}

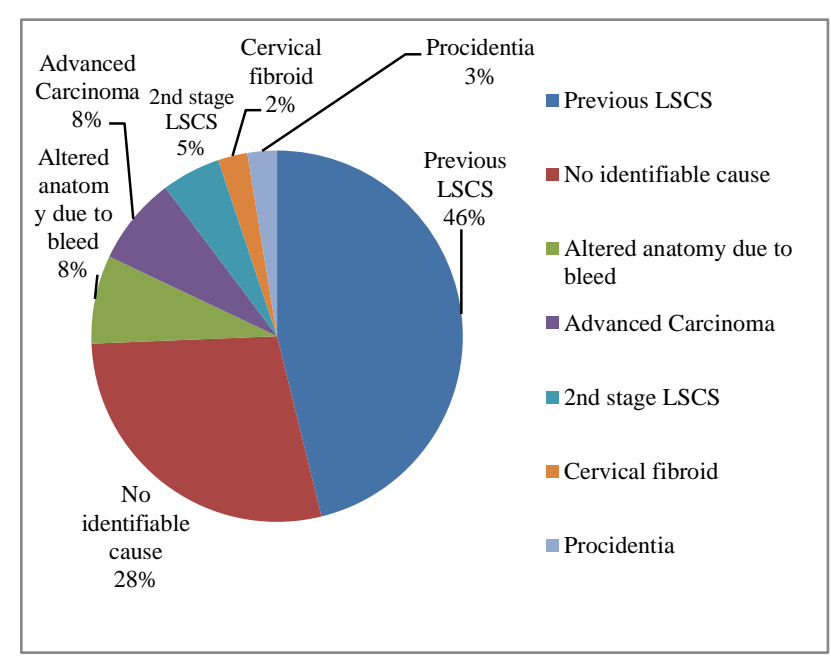

Figure 1: Risk factors for urological injuries.

In gynaecologic procedures, the incidence of bladder injury was highest in radical hysterectomy (2 out of 79, $2.5 \%$ ) followed by TLH/LAVH (4 out of 299, 1.3\%), NDVH (7 out of $490,1.4 \%$ ) TAH ( 5 out of $1360,0.37 \%$ ), laparotomy (1 out of $347,0.29 \%$ ), VH (3 out of 1529 , $0.2 \%$ ) and DHL. Out of total 4 ureteric injuries, three ureteric injuries were noted in cases of TLH/LAVH (3 out of 299) and one in a case of TAH. There were no urologic injuries noted in myomectomy, surgery for vault prolapse and Fothergill's operations. Most urinary bladder injuries occurred in patients with previous one or two caesarean sections, where bladder was adherent to anterior uterine wall and plane of dissection was lost, or due to dense adhesions due to infections( pelvic inflammatory disease) (Diagram 1). All but one urinary bladder injuries in gynaecologic procedure were identified intra-operatively and primary repair was done. In one case of NDVH (being carried out for abnormal uterine bleeding), the patient had a previous caesarean scar, bladder injury was identified post operatively when patient presented with VVF. Repair of VVF was done vaginally.

Most of the ureteric injuries occurred while performing laparoscopic hysterectomies. In one case, thermal injury to the ureter was identified 3 weeks postoperatively when patient presented with fever, abdominal pain and abdominal collection. Ureteric fistula was suspected, confirmed with cystography and ureteric stenting done for 3 weeks and patient recovered subsequently. Transection of ureter in lower third occurred in other two 
cases, both on left side, one of which was identified intraoperatively. Laparoscopic surgery was abandoned and it was converted to laparotomy, end to end anastomosis of ureter was done. In the other case of transection, ureteric injury was identified postoperatively when patient presented with abdominal collection after two weeks and cystography showed urinary leak, end to end anastomosis was done but ureter had leak again. Then a second surgery for ureteric re-implantation was done after which the patient recovered. In one case ureter got injured while performing $\mathrm{TAH}$, it was diagnosed during surgery. Uretero-neocystostomy was performed during the same surgery and patient had no complications subsequently.

\section{DISCUSSION}

In our study incidence of bladder injury and ureteric injuries in gynaecologic surgeries was $0.48 \%$ and $0.08 \%$ respectively, whereas in obstetric procedures the incidence of bladder and ureteric injuries was $0.1 \%$ and $0 \%$ respectively. This is lower than the overall incidence of urological injuries reported as varying from 0.5$1.5 \% .^{5,6}$ Raut and his associates quoted an incidence of bladder and ureteric injuries in gynaecologic surgeries as $1.23 \%$ and $0.11 \%$ respectively, whereas in obstetric procedures incidence of bladder injury was reported as $0.67 \%$ and ureteric injury as $0.33 \%$.

We noted 1 bladder injury out of 8 obstetric hysterectomies, which is highest incidence across all surgeries. Other studies also have noted high incidence bladder and ureteric injuries of $6.1 \%$ and $1.5 \%$ respectively for obstetric hysterectomies. ${ }^{8}$ Difficulty in identifying anatomy due to presence of blood in the surgical field is primary risk in these cases. In gynaecological surgeries, radical hysterectomy was associated with highest incidence of $2.5 \%$, which fairly correlates with incidence reported in literature. ${ }^{9}$ High incidence in such surgery can possibly be attributed to the fact that, not only wide dissection were performed during surgery, but also that there may be extensive pelvic adhesion and altered pelvic configuration produced by gynaecologic cancer. In open surgeries for benign conditions (leiomyoma being most common cause), highest rate of urinary injuries occurred following NDVH $(1.43 \%)$, followed by TAH $(0.37 \%)$ and $\mathrm{VH}(0.27 \%)$. Carley and associates noted that the incidence of bladder and ureteric injuries was $0.58 \%$ and $0.36 \%$ respectively in abdominal hysterectomy, $1.86 \%$ and $0 \%$ in vaginal hysterectomy. ${ }^{10}$ Previous studies have shown the overall incidence of bladder injury is about $0.26 \%$ and ureteric injury is about $0.16 \%$ in all kind of hysterectomies. ${ }^{11}$ Their incidence increases with use of intraoperative cystoscopy as many more cases are diagnosed early during the surgery. There were total 7 urological injuries out of 299 cases of TLH/LAVH. Both bladder and ureteric injuries incidence correlate with the incidence reported few years back, but it is higher than the recently reported incidence of urologic injuries in laparoscopic hysterectomies. ${ }^{12}$ Other studies also suggest laparoscopic surgeries have increased the incidence of urologic injuries to some extent, although with achievement of the learning curve, the frequency of bladder injury has declined but that of ureteric injury is still high. ${ }^{4}$

Bladder injuries are more common than ureteric injuries. There were 37 bladder injuries (together in obstetric and gynaecological surgeries) and 34 of them were identified intra-operatively. The remaining 3 patients presented postoperatively as fistulas. Primary repair of bladder heals well without much late sequels. Hence it is important to identify bladder injuries intra-operatively and perform primary repair to minimise morbidity to the patient. We noted three of the four ureteric injuries happened in cases of TLH/LAVH and one in case of TAH. Previous studies also have shown higher incidence of ureteric injuries in TLH compared to traditional hysterectomies. ${ }^{3}$ Contrary to urinary bladder injuries, ureteric injuries were not diagnosed intra-operatively (in 2 out 3 cases). This concurs with other literature, which also states ureteric injuries are rarely diagnosed intraoperatively ${ }^{13}$. Intra-operatively recognised injuries are usually more easily repaired at the time without the need for a second surgical intervention. The delay in the diagnosis leads to increase in morbidity, prolonged hospital stay and repeat surgery ${ }^{14}$. With the improvement in endo-urologic procedure, most of these can be managed by stenting. With the advent of ureteric reimplantation, nephrostomy, even complete transactions, diagnosed late postoperatively were also managed effectively. ${ }^{15}$ Since ureteric injuries are not always easy to identify, high index of suspicion must be maintained in patients with unexplained haematuria, fever, abdominal or flank pain and poor urine output. Regardless of the aetiology of urological damage, prompt radiological investigation in the form of intravenous urography or contrast-enhanced computed tomography is ultimately required for diagnosis to prevent delay in treatment. There were three case of bladder injury presenting as VVF in our series. One case was following NDVH, second following LSCS and third case following radical hysterectomy. The cases presented about 3 days to 30 days postoperatively as urine leak. All the cases needed secondary repair, with assistance from urologists. All three VVF healed uneventfully. Incidence of VVF in our series is comparable with other studies.

There are many possible causes for these urological injuries. In $50 \%$ cases of bladder injury, patients had previous LSCS scar and difficulty in dissection caused by the adhesion due to previous LSCS as the most common contributing factor. Scarring from previous surgery obliterates the safe surgical plane, thus making the dissection difficult. Sharp dissection close to the uterus avoids in advertent opening of bladder. Carcinomas, cervical fibroid, procidentia, non-progression in $2^{\text {nd }}$ stage of labour were other risk factors noted in our study. Previous studies have shown higher incidence of urologic injuries in surgery for prolapse and procidentia ${ }^{16}$. All the three ureteric injuries happened in lower third of ureter 
and most likely were caused by thermal injury during laparoscopy. This correlates with other studies which have noted the most common sites of ureteral injury during hysterectomy was along the pelvic wall lateral to the uterine artery, the area of uretero-vesical junction, and the base of infundibulopelvic ligament. ${ }^{17}$ Thorough knowledge of pelvic anatomy, being close to the uterus when coagulating, intraoperative cystoscopy and dissecting ureter throughout its course in difficult cases are recommended as measures to avoid ureteric injuries. Operating surgeons experience is one of the contributing factors for complications. ${ }^{18}$ But different surgeries have different learning curves. Hence it very difficult to define minimum how many cases need to be performed by the surgeon to be called as experienced surgeon. Therefore we did not analyse this data. At least few cases of urologic injuries in NDVH and laparoscopic surgeries in our series were attributable to inadequate experience of surgeon. We expect surgeon experience to be one of the determinants of complication rate.

Eight of the 41 patients needed blood transfusion, which is relatively high incidence of blood transfusion for such surgeries. The average hospital stay was also higher than anticipated for the respective category of the surgery. This higher incidence of transfusion and longer hospital stay can be attributed to urologic injury.

In conclusion, even though urological injuries are statistically rare, they are responsible for significant morbidity. Bladder injuries are more common, but are easy to manage with earlier diagnosis. Ureteric injuries which are usually diagnosed late and hence cause more morbidity than bladder injuries. Being more cautious and high degree of suspicion can help early diagnosis and avoid the sequel.

\section{Funding: No funding sources}

Conflict of interest: None declared

Ethical approval: The study was approved by the Institutional Ethics Committee

\section{REFERENCES}

1. Thompson JD. Operative injuries to the ureter: prevention, recognition, and management. In: Rock JA, Thompson JD. TeLinde's operative gynecology. 8th ed. Philadelphia: Lippincott Williams and Wilkins; 1997:1135-74.

2. Gilmour DT, Dwyer PL, Carey MP. Lower urinary tract injury during gynecologic surgery and its detection by intraoperative cystoscopy. Obstet Gynecol. 1999;94:883-9.

3. Harkki-Siren P, Sjoberg J, Tiitinea A. Urinary tract injuries after hysterectomy. Obstet Gynecol. 1998;92:113-8.
4. Purandare CN. Urological injuries in gynecology. J Obstet Gynecol India. 2007;57:203-4.

5. Frankman EA, Wang L, Bunker CH, Lowder JL. Lower urinary tract injury in women in the United States, 1979-2006. Am J Obstet Gynecol. 2010;202:495.e1-5.

6. Ozdemir E, Ozturk U, Celen S, Sucak A, Gunel M, Guney G, et al. Urinary complications of gynecologic surgery: iatrogenic urinary tract system injuries in obstetrics and gynecology operations. Clin Exp Obstet Gynecol. 2011;38:217-20.

7. Raut V, Shrivastava A, Nandanwar S, Bhattacharya M. Urological injuries during obstetric and gynaecological surgical procedures. J Postgrad Med. 1991;37:21-3.

8. Sahito RA, Memon GA, Khaskheli MS. Urological Injuries during Obstetrical and Gynecological Surgeries. ANNALS. 2011;17:218-22.

9. Lee JS, Choe JH, Lee HS, Seo JT. Urologic Complications Following Obstetric and Gynecologic Surgery. Korean Journal of Urology. 2012;53:795-9.

10. Carley ME, McIntire D, Carley JM, Schaffer J. Incidence, risk factors and morbidity of unintended bladder or ureter injury during hysterectomy. Int Urogynecol J Pelvic Floor Dysfunct. 2002;13(1):1821.

11. Gilmour DT, Dwyer PL, Carey MP. Lower urinary tract injury during gynecologic surgery and its detection by intraoperative cystoscopy. Obstet Gynecol. 1999;94:883-9.

12. Adelman MR, Bardsley TR, Sharp HT. Urinary tract injuries in laparoscopic hysterectomy: a systematic review. J Minim Invasive Gynecol. 2014;21:558-66.

13. Mann WJ, Arato M, Patsner B, Stone ML. Ureteral injuries in obstetrics and gynecology training program: Etiology and management. Obstet Gynecol. 1988;72:82-5.

14. Selzman AA, Spirnak JP. Iatrogenic ureteral injuries: a 20-year experience in treating 165 injuries. J Urol. 1996;155:878-81.

15. Liapis A, Bakas P, Giannopoulos V, Creatsas G. Ureteral injuries during gynecological surgery. Int Urogynecol J Pelvic Floor Dysfunct. 2001;12:391-4.

16. Vakili B, Chesson RR, Kyle BL, Shobeiri SA, Echols KT, Gist R, Zheng YT, Nolan TE. The incidence of urinary tract injury during hysterectomy: a prospective analysis based on universal cystoscopy. Am J Obstet Gynecol. 2005;192:1599-604.

17. Berkmen F, Peker AE,Alagol H, Ayyildiz A, Arik AI,Basay S. Treatment of iatrogenic ureteral injuries during various operations for malignant conditions. J Exp Clin Cancer Res. 2000;19:441-5.

18. Chapron C, Pierre F, Querleu D, Dubuisson JB. Complications of laparoscopy in gynecology. Gynecol Obstet Fertil. 2001;29:605-12.

Cite this article as: Desai RS, Sunil Kumar K.

Urological injuries during obstetric and gynaecological procedures: A retrospective analysis over a period of eleven years. Int J Reprod Contracept Obstet Gynecol 2016;5:1916-20. 